\title{
Extractible self-expandable metal stent in the treat- ment of Crohn's disease anastomotic strictures
}
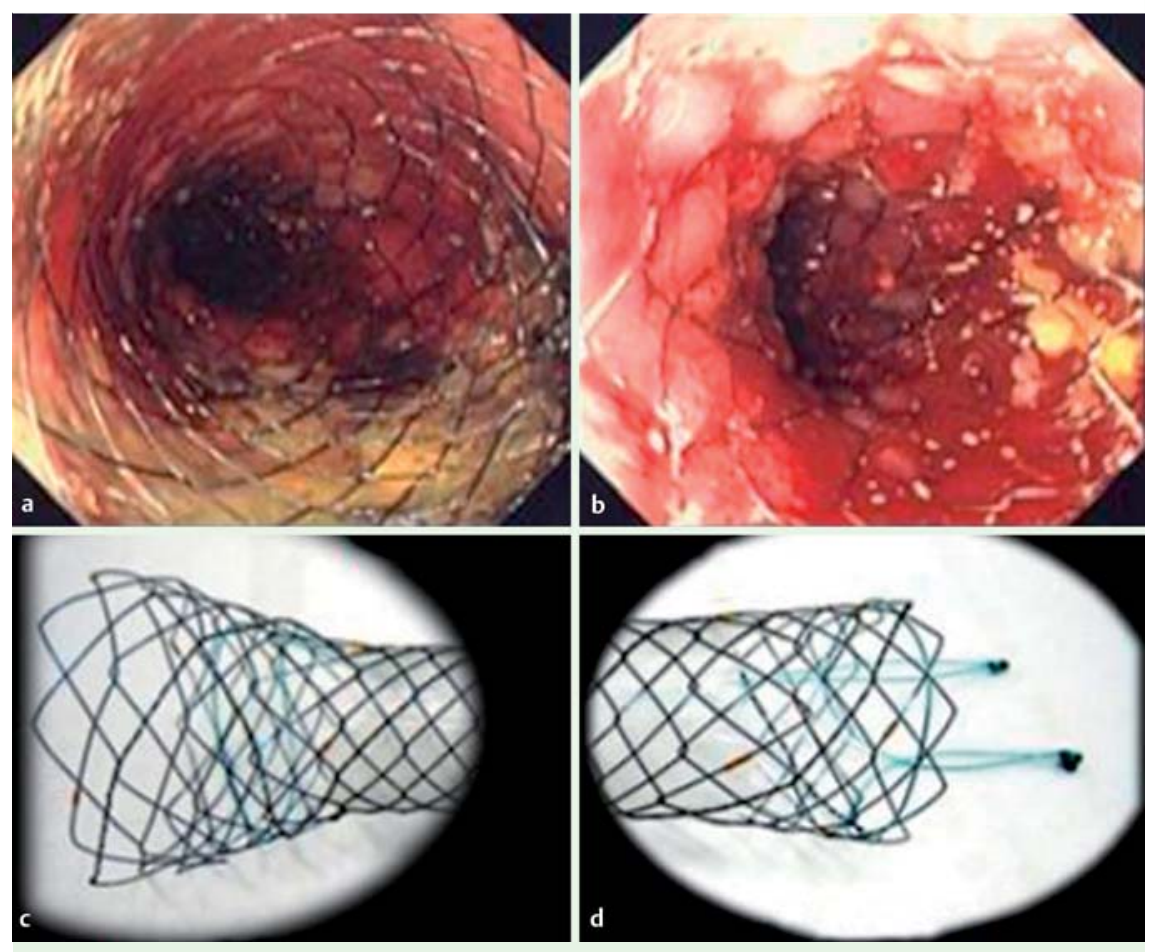

Fig. 1 Anti-migratory colonic Hanarostent: a set up, b after withdrawal, c large asymmetric distal head, $\mathbf{d}$ proximal double lasso.

Stricture at the site of the ileocolonic anastomosis is a common complication in patients with Crohn's disease after surgical resection. In these patients, endoscopic balloon dilation has been developed as an alternative to iterative surgery. The rate of immediate success is excellent, but consecutive dilations are required in $50 \%$ of cases [1]. First attempts to increase the efficacy of dilation long term by using a fully covered self-expandable metal stent (SEMS) have failed because of early stent migration [2]. Here we report on our preliminary experience of a new stent that includes an antimigratory design, in patients with postsurgical ileocolonic Crohn's disease stricture.

The Hanarostent stent (M.I. Tech, Seoul, Korea) is a through-the-scope partly covered SEMS (labelled CE) - $80 \mathrm{~mm}$ long and $20 \mathrm{~mm}$ in diameter - with an antimigratory design that comprises a non- covered 40-mm diameter distal (ileal) collar and a noncovered 26-mm diameter proximal (colonic) one ( Fig. 1). In order to limit the impaction of its non-covered part, the stent is systematically removed 7 days after placement.

Seven patients ( 4 men, 3 women), median age 50 years (36-59), were treated between June 2010 and June 2011.The median duration of Crohn's disease was 20 years $(14-29)$. Five patients had a right ileocolonic resection and two a subtotal colectomy with ileosigmoid anastomosis. The median time since last surgery was 12 years $(4-16)$. All patients had obstructive symptoms despite previous dilations (1-7 sessions), with a relapse of symptoms after a median time of 5 months (1-41) since the last dilation. At endoscopy and computed tomography (CT) scan, there was no evidence of disease activity apart from the presence of an anastomotic stricture less than $5 \mathrm{~cm}$ long. Four patients were receiving no treatment, and three were on maintenance therapy with infliximab. Informed consent was obtained from all patients.

With the patients under general anesthesia, through-the-scope stenting was easily performed ( $\bullet$ Fig. 2) under fluoroscopic guidance. Three patients experienced abdominal pain for 2 days. The stent was successfully withdrawn in all patients after 7 days: it was pulled out by the tow wire, and carefully through the colon. No migration of the stent was observed in between. No other complications occurred. Complete relief of obstructive symptoms was achieved in all patients. After a median time of 10 months (6-18), two patients had recurrent symptoms, minor in one case, obstructive in the other, leading to a new session of endoscopic dilation in only one of seven patients at the time of writing.
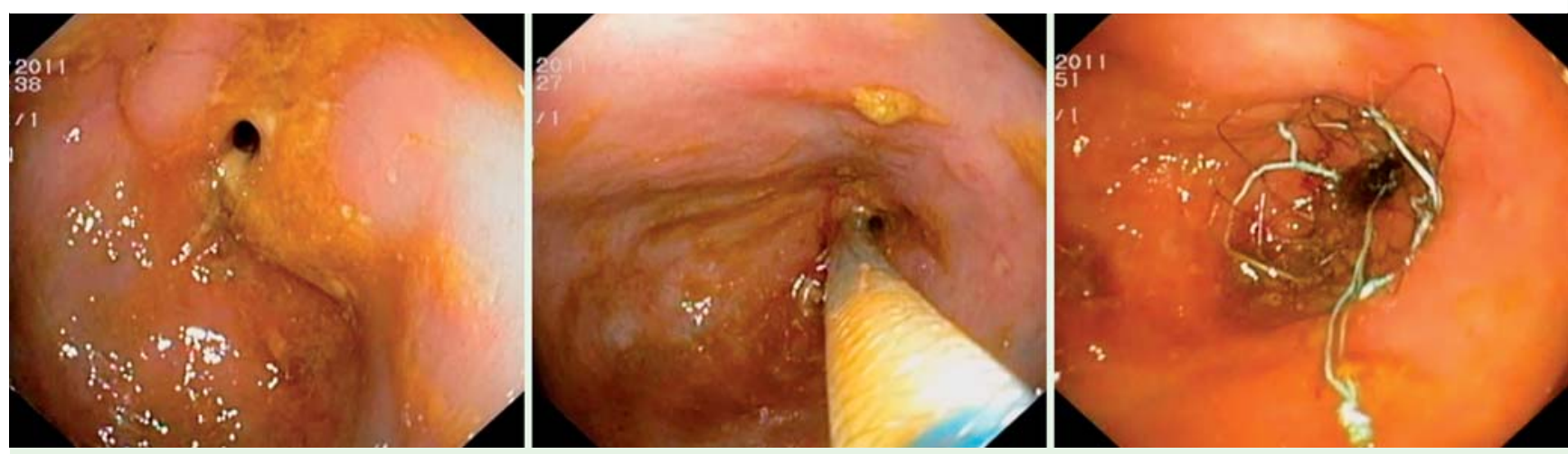

Fig. 2 Insertion of through-the-scope stent into anastomotic stricture in Crohn's disease. 


\section{Endoscopy_UCTN_Code_TTT_1AQ_2AF}

Competing interests: None

J. Branche ${ }^{1}$, A. Attar ${ }^{2}$, G. Vernier-Massouille', P. Bulois ${ }^{3}$, J.-F. Colombel ${ }^{1}$, Y. Bouhnik ${ }^{2}$, V. Maunoury ${ }^{1}$

${ }^{1}$ Gastroenterology Department, Lille University Hospital, Hôpital Huriez, Lille, France

${ }^{2}$ Gastroenterology Department, Hôpital Beaujon, Clichy, France

${ }^{3}$ Gastroenterology Department, Hôpital Saint Philibert, Lomme, France

\section{References}

1 Scimeca D, Mocciaro F, Cottone $M$ et al. Efficacy and safety of endoscopic balloon dilation of symptomatic intestinal Crohn's disease strictures. Dig Liver Dis 2011; 43: $121-125$

2 Attar A, Maunoury V, Vahedi K et al. Safety and efficacy of self expandable metallic stents in the treatment of Crohn's disease intestinal strictures. Inflamm Bowel Dis, in press 2011

\section{Bibliography}

DOI http://dx.doi.org/ 10.1055/s-0032-1309854 Endoscopy 2012; 44: E325-E326

(c) Georg Thieme Verlag KG Stuttgart · New York ISSN 0013-726X

\section{Corresponding author}

\section{Maunoury, MD}

Gastroenterology Department Lille University Hospital

Hôpital Huriez

Lille 59037

France

Fax: +33-3-20444975

vincent.maunoury@chru-lille.fr 